EM

\title{
SABERES DOCENTES NA EDUCAÇÃO GEOGRÁFICA ESCOLAR ${ }^{1}$
}

\section{TEACHING KNOWLEDGE ON THE SCHOOL GEOGRAPHIC EDUCATION}

\author{
Mariana Pricilia DE ASSIS ${ }^{2}$ \\ Cícero Moreira DA SILVA ${ }^{3}$
}

\begin{abstract}
Resumo: Este artigo faz parte de um ensaio teórico sobre os saberes esperados para a transposição didática do professor em sala de aula. Ele tem como objetivo trazer uma contribuição para alunos e professores dos campos de conhecimento relacionados às ciências sociais e humanas, oferecendo algumas sugestões sobre as práticas educativas e os meios para o entendimento. Partimos do pressuposto que é de suma relevância compreender o impacto dos saberes docentes para a prática pedagógica, especificando no viés sobre a possibilidade de os saberes serem ampliados para ressignificar a prática educativa do professor de Geografia. Este estudo faz parte da pesquisa referente à dissertação que está em processo de construção do Mestrado no Programa de Pós-Graduação em Ensino -PPGE, da Universidade do Estado do Rio Grande do Norte-UERN. Ele é de caráter bibliográfico com composição teórica relacionada com o tema. Nessa perspectiva, os resultados obtidos nesse estudo apontam que os saberes docentes são dotados de significância ao serem aperfeiçoados durante a construção do conhecimento em sala de aula e possibilitam um possível agir pedagógico construtivista.
\end{abstract}

Palavras-Chaves: Saber docente; Agir pedagógico; Educação geográfica.

\begin{abstract}
This article is part of a theoretical essay on the expected knowledge for the didactic transposition of the teacher in the classroom. It aims to bring a contribution to students and teachers in the fields of knowledge related to the social and human sciences, offering some suggestions on educational practices and the means for understanding. It is based on the assumption that it is of utmost importance to understand the impact of teaching knowledge for pedagogical practice, specifying in the bias about the possibility of the knowledge being expanded to resignify the educational practice of the Geography teacher. It is part of the research related to the dissertation that is in the process of construction of the Master degree in the Graduate Program in Teaching from the Universidade Estadual do Rio Grande do Norte. This work is from bibliographic character with theoretical composition related to the theme. Therefore, the results obtained point out that the teaching knowledge is endowed with significance when it's improved during the construction of knowledge in the classroom and enables a possible constructivist pedagogical action.
\end{abstract}

Keywords: Teaching Knowledge; Pedagogical Acting; Geographic Education.

\footnotetext{
${ }^{1}$ Artigo resultado da pesquisa bibliográfica da dissertação que está em processo de construção do Mestrado no Programa de Pós-Graduação em Ensino -PPGE, da Universidade do Estado do Rio Grande do Norte- Campus Avançado Pau dos Ferros-CAPF.

${ }^{2}$ Mestranda do Programa de Pós Graduação em Ensino-PPGE, pela Universidade do Estado do Rio Grande do Norte- Campus Avançado de Pau dos Ferros - CAPF. Bolsista do Programa de Pós-Graduação em Ensino-PPGE -Órgão Financiador: Coordenação de Aperfeiçoamento de Pessoal de Nível Superior (CAPES). Possui graduação em Geografia pela Universidade do Estado do Rio Grande do Norte - Campus Avançado de Pau dos FerrosCAPF. E-mail: maryeduca93@gmail.com - https://orcid.org/0000-0001-8104-6956.

${ }^{3}$ Doutor em Geografia pela Universidade Federal do Ceará (UFC); Professor da Universidade do Estado do Rio Grande do Norte - Brasil; Professor do Programa de Pós-Graduação em Ensino (PPGE); Pesquisador do Núcleo de Estudos de Geografia Agrária e Regional (NuGAR). E-mail: ciceronilton@yahoo.com.br https://orcid.org/0000-0001-6773-7451.
} 


\section{Introdução}

Este estudo parte do pressuposto que ensinar é partilhar e mobilizar saberes que são construídos pelo professor no ofício da prática docente em sala de aula. Desse modo, o mediador constrói saberes educativos diante do contexto escolar que vivencia. É nesse sentido, que este artigo proporciona a compreensão sobre a significância que os saberes docentes dos professores de Geografia possuem para possibilitar uma educação geográfica com sentido para os estudantes.

Fazer educação geográfica requer o esforço de superar o simples ensinar Geografia passando apenas conteúdos, é a busca de caminhos que possibilitem aos alunos a significância do saber geográfico para suas vidas (CALLAI, 2010).

$\mathrm{Na}$ contemporaneidade, o ensino de Geografia reflete um cenário em constante dinâmica e mudanças na produção do espaço geográfico que culmina em novas reflexões sobre a prática docente em sala de aula.

Diante disso, surgem algumas inquietações: qual a relevância dos saberes para a prática educativa significativa dos professores de Geografia em sala de aula? E qual o significado que os saberes docentes têm para a formação inicial e continuada do educador e, consequentemente, para a competência pedagógica do mediador na educação geográfica dos estudantes?

Sendo assim, este estudo se norteia na perspectiva de investigar os saberes e suas implicâncias nas atividades de interações no ambiente educativo através da composição teórica. Assim sendo, nesse estudo, acredita-se que os saberes docentes, ao serem ampliados, podem ser uma oportunidade de construir possíveis caminhos para uma prática educativa construtivista pelo professor em sala de aula.

O professor construtivista deve conhecer a matéria que ensina, entretanto, por uma razão diferente de que se imagina. Agora, trata-se de saber bem para discutir, para localizar na história da ciência o ponto correspondente ao pensamento dela, para fazer perguntas "inteligentes", para formular hipóteses, para sistematizar quando necessário (MACEDO, 1994).

É nesse viés que os diferentes tipos de saberes que os professores mobilizam nos atos comunicativos em sala de aula culminam de forma relevante no fortalecimento da prática docente. Desse modo, o saber docente, nesse artigo, se centraliza na ideia que os saberes dos 
EM

QUESTÃO

V.14 N. $01 \bullet 2021$

pág. 58-76

professores de Geografia são permeados de significados e que isso corresponde a um possível caminho pedagógico para construir uma prática educativa significativa no contexto escolar.

O saber docente se desenvolve no espaço do outro e para outro. Em suma, os saberes dos professores são plurais e heterogêneos porque envolvem conhecimentos e um saber-fazer bastante diversos, provenientes de fontes variadas e de natureza diferente (TARDIF, 2011).

Sendo assim, a prática docente no cotidiano escolar é uma ação que oportuniza identificar elementos e condicionantes que interferem na construção dos saberes em sala de aula. No presente ensaio teórico, investiga-se como os saberes docentes influenciam para um agir pedagógico condizente com a realidade do cotidiano escolar dos educandos, assim como possibilita a didática destes saberes para efetivar a prática educativa no espaço escolar.

Ao incluir diferentes saberes na ação docente na construção dos saberes geográficos em sala de aula, possibilita-se caminhos metodológicos para proporcionar aprendizagem geográfica com sentido para os estudantes no espaço escolar.

Uma prática pedagógica inovadora permite o aluno observar, descrever, comparar e analisar os fenômenos observados na realidade cotidiana e, consequentemente, desenvolvendo habilidades intelectuais complexas, como por exemplo: fazer correlação dos conceitos geográficos frente à realidade (CASTELAR, 2010).

As pesquisas científicas nos últimos anos têm intensificado estudos direcionados à investigação da prática docente no espaço escolar e sua importância na construção dos saberes escolares. É nesse fundamento que pesquisas universitárias centralizam o campo de estudo na escola e intensificam pesquisas empíricas, objetivando compreender a significância da ação docente na construção do saber em sala de aula. É nessa perspectiva que a pesquisa no ambiente educativo rompe com o caráter descontextualizado que perdurou em décadas anteriores no Brasil, norteada por investigações com embasamento teórico sem incluir a escola como campo de estudo.

No Brasil, a partir do início dos anos 90, a pesquisa educacional passou a vislumbrar a sala de aula como um espaço rico em possibilidades de investigação. Sendo assim, um número cada vez maior de pesquisadores da área da educação tem ido regularmente às instituições escolares observar e analisar as atividades cotidianas dos trabalhadores do ensino. É nessa vertente que estamos muito longe das antigas abordagens normativas ou experimentais e mesmo behavioristas, que confinavam o estudo do ensino às variáveis mediadas em laboratórios. Tanto na Europa, como no Brasil, todo o campo da Ergonomia encontrava-se atualmente em pleno desenvolvimento (TARDIF, 2011). 
Sendo assim, percebe-se que os estudos direcionados à prática educativa ao longo do tempo foram abrindo espaço para a análise no campo escolar, favorecendo o avanço do entendimento sobre a importância de incluir o contexto escolar como um espaço de pesquisa e investigação científica. É nessa vertente que o agir pedagógico dos professores e sua influência para o ensino escolar é objeto de estudo nas pesquisas. No caso desse artigo, centraliza-se em compreender, através da composição teórica, a implicância dos saberes docentes para a transposição didática do professor de Geografia ao mediar o saber geográfico.

O motivo de contextualizar os saberes docentes e sua influência para as práticas educativas dos professores de Geografia como objeto de estudo surgiu da experiência vivenciada no estágio supervisionado I de observação e II de regência em Geografia, em uma escola pública, onde foi possível verificar a implicância dos saberes na competência pedagógica dos mediadores nas aulas de Geografia, assim como para o desenvolvimento da aprendizagem dos estudantes. Entendemos que a ampliação dos saberes mobilizados na prática culmina com possíveis caminhos para construir o saber geográfico.

Diante disso, outro elemento que contribuiu para o presente artigo é o fato de a pesquisa estar sendo desenvolvida na dissertação no Programa de Pós-Graduação em EnsinoPPGE. A pesquisa tem como propósito investigar a implicância dos saberes docentes para a competência pedagógica do professor, assim como, para a aprendizagem geográfica dos estudantes. Neste viés, a referente trajetória acadêmica é fundamental para a escolha do objeto do presente estudo contextualizado através do ensaio teórico.

Sendo assim, esta pesquisa objetiva compreender a significância dos saberes docentes para as práticas educativas dos professores de Geografia, identificando, no ensaio teórico, os diferentes tipos de saberes que são construídos durante a experiência no espaço escolar de atuação, assim como, no espaço acadêmico da formação e nos demais espaços informais que, porventura, são permeados de significados para o fortalecimento da competência pedagógica do mediador. Assim, investiga-se sobre os saberes mobilizados na prática docente através das vertentes dos respectivos autores.

Este artigo está estruturado em três seções: a (i) primeira contextualiza o impacto dos saberes docentes na construção do saber geográfico no espaço escolar. A (ii) segunda seção possibilita compreender as competências pedagógicas dos saberes docentes na educação geográfica escolar. Por fim, a (iii) terceira seção enfatiza a construção dos saberes no processo formativo do professor de Geografia. 
O percurso trilhado da pesquisa deste artigo segue os parâmetros determinados por Lakatos e Marconi (2003), quando apontam que a pesquisa bibliográfica se constitui como um apanhado geral sobre os principais trabalhos realizados na área temática posto em investigação.

A composição teórica desse artigo fundamenta-se em Alarcão (2011), que enfoca os professores reflexivos em uma escola reflexiva; Tardif (2011), que salienta os saberes docentes e o agir pedagógico do professor no espaço escolar; Sacramento (2010), que contextualiza a didática no ensino de Geografia; Charlot (2014) sobre o saber e as práticas educativas; Freire (2002) na perspectiva dos saberes necessários para a prática educativa, dentre outros teóricos. A pesquisa é do tipo qualitativa que, segundo Gerhardt e Silveira (2009, p. 32):

As características da pesquisa qualitativa são: objetivação do fenômeno [...] compreender, explicar, precisão das relações entre o global e o local em determinado fenômeno; observância das diferenças entre o mundo social e o mundo natural.

Sendo assim, o percurso metodológico que o presente trabalho trilhou parte de uma pesquisa da revisão de literatura com ensaio teórico sobre o objeto do estudo que está sendo desenvolvido na pesquisa do mestrado em ensino acerca dos saberes docentes e aprendizagem geográfica.

\section{Saberes docentes na construção do saber geográfico no espaço escolar}

A presente seção possibilita o sujeito compreender a relevância dos saberes docentes na educação geográfica escolar. Partimos da perspectiva que assinala que o professor de Geografia, ao construir sua prática em sala de aula, mobiliza saberes que culminam na consolidação da identidade docente no espaço escolar, assim como auxilia a construção do saber geográfico com mais sentido para o educando.

[...] o saber dos professores não é um conjunto de conteúdos cognitivos definidos de uma vez por todas, mas um processo em construção ao longo de uma carreira profissional na qual o professor aprende progressivamente a dominar seu ambiente de trabalho, ao mesmo tempo em que se insere nele e o interioriza por meio de regras de ação que se tornam parte integrante de sua "consciência prática" (TARDIF, 2011, p. 14). 
A prática educativa no espaço escolar é permeada de desafios a serem superados. Dentre eles, considerar o saber dos educandos como parte integrante do processo ensinoaprendizagem para desenvolver a ação pedagógica no ambiente educativo. Outrossim, construir e aplicar, não apenas o saber geográfico no exercício da prática docente, mas também mobilizar os saberes que são adquiridos na experiência do cotidiano escolar, pois o saber construído no exercício da prática educativa em sala de aula desempenha um papel de suma relevância para a construção de um agir pedagógico mais condizente com a realidade do ambiente educativo.

Pensar Didática da Geografia é saber organizar os saberes geográficos e articulá-los com os saberes pedagógicos, buscando relacioná-los, ainda, com o saber do professor, o saber do aluno e o saber escolar. As ações realizadas promovem essas inter-relações para que a perspectiva de ensino e aprendizagem de Geografia seja concretizada (SACRAMENTO, 2010, p. 4).

Nesse tocante, a didática do professor mediador incorpora os saberes de forma plural na sua prática e também constrói caminhos metodológicos que serão significantes para promover uma educação geográfica com significado para a vida dos educandos. É sabido que as situações em sala de aula exigirão a mobilização do saber geográfico, porém, não apenas um tipo de saber, posto que o saber pedagógico adquirido na experiência do docente no espaço escolar e o saber do aluno são saberes integrantes e relevantes para construir a prática educativa.

Sendo assim, construir caminhos metodológicos para que as abordagens teóricas auxiliem no fazer pedagógico significativo do professor em sala de aula exige uma reestruturação da forma de apreender e ensinar em sala de aula. Neste sentido, permite-se superar dilemas de correntes das décadas anteriores, quando prevalecia o educar na cultura de ensino que remetia a instrumentalizar o cidadão para atender as demandas produtivas no mundo do trabalho.

A maior mudança da escola na época contemporânea já ocorre nas décadas de 1960 e 1970 e, portanto, é anterior à globalização. Consiste em pensar a escola na lógica econômica e social do desenvolvimento. Antes da Segunda Guerra Mundial, o Estado, na sua relação com a educação, permanece um Estado Educador: pensa a educação em termos de construção da nação, paz social e inculcação de valores. A partir dos anos 1950 e, sobretudo, 1960, ele se torna Estado Desenvolvimentista: claramente (França, Japão, Coreia do Sul, Brasil etc.) ou de forma disfarçada (Estados Unidos), ele pilota o crescimento econômico e coloca a educação a serviço do desenvolvimento. Essa política encontra um amplo consenso social, por gerar novos empregos qualificados, que uma escolaridade mais longa permite ocupar e, portanto, 
por satisfazer as classes médias e despertar esperanças nas classes populares (CHARLOT, 2014, p. 21).

Desse modo, é perceptível que, em décadas anteriores, a formação escolar passa a ser um instrumento para aperfeiçoar o conhecimento e possibilitar competências e habilidades para os sujeitos serem incluídos no mundo do trabalho.

Diante desse contexto, detecta-se que, após os conflitos territoriais nos países ocidentais, o espaço escolar passa a ser um instrumento para atender ao sistema do trabalho vigente. Assim, o mundo denominado contemporâneo e veloz, com desenvolvimento maciço, gera impacto como, por exemplo, a concentração de indústrias nos espaços que culmina para enquadrar os estudantes à lógica e necessidade do sistema. Conquanto, outros discursos passam a ser incorporados nessa fase como uma forma de resistência da comunidade escolar de aderirem a um currículo que se descontextualizava do mundo vivido do educando.

A partir do final da década de 1970, no Brasil, generaliza-se entre os professores a expectativa em torno de buscar alternativas para superar o sistema implantado no ambiente educativo, à medida que se tornam evidentes a insuficiência, a inadequação e a inviabilidade da orientação oficial. A pedagogia oficial que se tentou generalizar é inconsistente, é passível de contestação, atende a interesses minoritários e também à tentativa dos grupos hegemônicos de impor a toda a sociedade a sua dominação. Assim, dada uma sociedade capitalista, sua educação reproduz os interesses do capital (SAVIANI, 2011).

É nesse sentido que é disseminado no contexto social e educacional uma reconstrução de ideias no sistema educativo, surgindo concepções de tornar o ensinar/aprender com mais sentido para o educado. É nesse advento que a escola tem como função incluir e democratizar o ensino. Desse modo, surgem desafios no espaço educativo, dentre eles o de atribuir sentido no agir pedagógico em sala de aula, que se torna uma prioridade no século XXI.

A escolarização, enquanto estratégia global possibilitando o acesso a funções sociais cobiçadas, não seria mais suficiente. Desse modo, surge, então, a necessidade de microsestratégias cujo desafio consistiria em determinar quais são os saberes socialmente pertinentes dentre os saberes escolares (TARDIF, 2011).

A sociedade contemporânea vivencia uma reestruturação de paradigmas nos campos sociais, políticos, econômicos e educacionais. Diante das mudanças impulsionadas por novos artefatos de idéias e posições, surgem teorias que possibilitam possíveis caminhos para efetivar práticas educativas que sejam mais condizentes com a realidade do sujeito que, porventura, é dotado de saberes construídos nos espaços escolares e extraescolares. 
$\mathrm{EM}$

Por isso é que, na formação permanente dos professores, o momento fundamental é o da reflexão crítica sobre a prática. É pensando criticamente a prática de hoje ou de ontem que se pode melhorar a próxima prática [...]. Quanto mais me assumo como estou assim, mais me torno capaz de mudar, de promover-me, no caso, do estado de curiosidade ingênua para o de curiosidade epistemológica (FREIRE, 2002, p. 22).

É nesse fundamento que a pluralidade dos saberes docentes é um instrumento que auxiliará o professor de Geografia na construção de um saber geográfico com mais sentido nas aprendizagens dos alunos.

\section{As competências pedagógicas dos saberes docentes na educação geográfica escolar}

Diante das mudanças na contemporaneidade, novas posturas dos mediadores no espaço escolar são exigidas. Ensinar é construir, junto com o educando, possibilidades de saberes que consolidam uma aprendizagem com significado para os sujeitos.

A competência para lidar com os meios de informação na sociedade da aprendizagem culmina na restruturação do papel do professor e do aluno, como também, a revisão do papel da escola. Assim, o aluno é um aprendente que procura o saber e encontra no ambiente educativo da sala de aula um espaço que possibilita a construção do saber (ALARCÃO, 2011).

É nesse sentido que as competências pedagógicas dos saberes docentes na sua pluralidade possibilitam uma educação geográfica na Geografia escolar. Diante desse contexto, no espaço escolar, o professor cotidianamente constrói saberes que promovem possíveis caminhos de estratégias metodológicas.

A prática educativa e o ensino são formas de agir plurais que mobilizam diversos tipos de ação aos quais estão ligados saberes específicos. Resulta desse postulado que o "saber-educar" e o "saber ensinar" também são saberes plurais nos quais estão presentes diversos saberes e diversas competências (TARDIF, 2011, p. 153).

Os saberes contextualizados de forma articuladora influenciarão na promoção das competências docentes, assim como permitirão o docente utilizar o saber de acordo com as situações do ambiente educativo. Desse modo, eles promovem um agir pedagógico estratégico através dos diferentes tipos de saberes que são construídos pelo professor em sala 
de aula. Contudo, o que determinará a aplicação de determinado saber é a situação que surgirá em sala de aula.

As escolas são lugares onde as novas competências devem ser adquiridas ou reconhecidas e desenvolvidas. A noção de que a competência é a capacidade de utilizar os saberes para agir em situação, constitui-se como mais-valia relativamente aos saberes. A competência não existe, portanto, sem os conhecimentos. Não se pode afirmar que as competências estão contra os conhecimentos, mas com os conhecimentos; elas se reorganizam-nos e explicitam a sua dinâmica e valor funcional (ALARCÃO, 2011).

Desse modo, é possível verificar a relevância do professor aplicar na construção do saber geográfico múltiplos saberes para construir uma prática educativa transformadora.

É nesse respaldo que elaboramos a partir da composição teórica dos saberes docentes de Tardif (2011), o quadro 01 diretivo que contribui para a prática educativa do professor de Geografia.

O correspondente quadro representa a didática dos saberes geográficos na sua pluralidade, sendo adaptado, aqui, aos saberes docentes direcionados para os professores de Geografia. Desse modo, é uma espécie de roteiro metodológico que direciona a reflexão sobre a implicância dos saberes construídos durante a formação inicial e continuada e sua relevância na prática docente nas aulas de Geografia. Assim, ampliamos, no presente estudo, a concepção dos saberes para contextualizá-lo com a realidade do cotidiano escolar.

Segundo Cavalcanti (2006, p. 27):

[...] por didática compreende-se, aqui, um campo de conhecimento que se ocupa da reflexão sobre o processo de ensino, prevalecendo o entendimento de ensino como uma prática social, dinâmica e subjetiva, cuja eficiência não está limitada a uma correta aplicação de regras gerais e procedimentos.

O quadro diretivo que segue apresenta a relevância do saber geográfico ser construído com a integração dos saberes. Entende-se, neste estudo, que o saber geográfico remete à importância do conhecimento acadêmico que o profissional adquiriu ao longo da formação. $\mathrm{O}$ saber escolar é proveniente do conhecimento do saber que se encontra nos livros e currículos, que direciona a prática do professor. Já os saberes geopedagógicos são os procedimentos metodológicos que o mediador utilizará para promover uma educação geográfica mais condizente com a realidade dos sujeitos. Por fim, os saberes experienciais referem-se às experiências que os professores têm durante o seu ofício profissional, que são adquiridos com a vivência com a turma e com os pares na instituição educativa. 
$\mathrm{EM}$

QUESTÃO

V.14 N. $01 \diamond 2021$

pág. 58-76

O saber docente pode ser compreendido como um conjunto de saberes heterogêneos com os aspectos sociais e individuais do professor. Sendo assim, esses saberes alicerçam a prática docente e, consequentemente, a formação dos professores das escolas de ensinos Fundamental e Médio. Diante desse fragmento, seu valor dependerá das dificuldades que os professores apresentam em relação à prática docente, assim como a relação com seu trabalho diário, tanto com seus alunos na sala de aula quanto com os demais atores atuantes no contexto escolar (PIRES, 2009).

Diante disso, o reconhecimento desses saberes favorece o entendimento das lacunas e a intervenção durante o processo de ensino/aprendizagem nas aulas de Geografia. Sendo assim, todos os tipos de saberes para a construção do conhecimento geográfico em sala de aula são de suma relevância.

Quadro 1 - Saberes Docentes no Ensino de Geografia.

\begin{tabular}{|c|c|c|}
\hline $\begin{array}{l}\text { Saberes da prática } \\
\text { docente }\end{array}$ & $\begin{array}{c}\text { Construção do saber no espaço } \\
\text { escolar }\end{array}$ & $\begin{array}{l}\text { Competência geopedagógica } \\
\text { sujeitos direcionados as } \\
\text { competências (professor e pares da } \\
\text { instituição educativa). }\end{array}$ \\
\hline $\begin{array}{c}\text { SABERES } \\
\text { GEOPEDAGÓGICOS }\end{array}$ & $\begin{array}{l}\text { Os saberes geopedagógicos são } \\
\text { provenientes da interface dos } \\
\text { saberes geográficos que são } \\
\text { construídos em sala de aula. } \\
\text { Apresentam competências para o } \\
\text { professor construir os caminhos } \\
\text { geopedagógicos para efetivar a } \\
\text { prática educativa significativa. } \\
\text { Nesse nível, é necessário o } \\
\text { domínio do saber geográfico; } \\
\text { porém, neste estágio, é de suma } \\
\text { relevância que o saber pedagógico } \\
\text { se sobressaia, para possibilitar } \\
\text { estratégias educativas que } \\
\text { promovam o desenvolvimento da } \\
\text { aprendizagem dos educandos. }\end{array}$ & $\begin{array}{c}\text { *Competência geopedagógica } \\
\text { Esse tipo de competência é } \\
\text { desenvolvido durante o exercício da } \\
\text { prática docente em sala de aula. } \\
\text { Ensinar, nessa fase, é construir saberes } \\
\text { e desenvolver a capacidade de } \\
\text { reconstruir a prática docente, de } \\
\text { acordo com a necessidade do grupo } \\
\text { social onde está sendo mediado o } \\
\text { saber. Nesse nível, o docente aprende } \\
\text { a metodologia fazendo. O espaço } \\
\text { social que constrói os saberes; } \\
\text { (Instituição Educativa; Escola). }\end{array}$ \\
\hline $\begin{array}{l}\text { SABERES } \\
\text { GEOGRÁFICOS }\end{array}$ & $\begin{array}{l}\text { Provenientes do arcabouço de } \\
\text { saberes aprendidos pelo docente } \\
\text { durante a formação. Nesse nível, o } \\
\text { sujeito obtém domínio da ciência } \\
\text { geográfica e dos conceitos-chave } \\
\text { da vertente geográfica. }\end{array}$ & $\begin{array}{l}\text { *Competência Instrumentalizadora } \\
\text { Aqui, o docente a constrói ao longo da } \\
\text { formação acadêmica. Ela é } \\
\text { desenvolvida durante a graduação, } \\
\text { período esse em que se aprendem os } \\
\text { conceitos-chave da ciência, os } \\
\text { paradigmas das correntes geográficas } \\
\text { e desenvolvem-se possibilidades de } \\
\text { integrar a Geografia Escolar. O espaço } \\
\text { social que constrói o saber é o ensino } \\
\text { superior (Universidade). }\end{array}$ \\
\hline
\end{tabular}




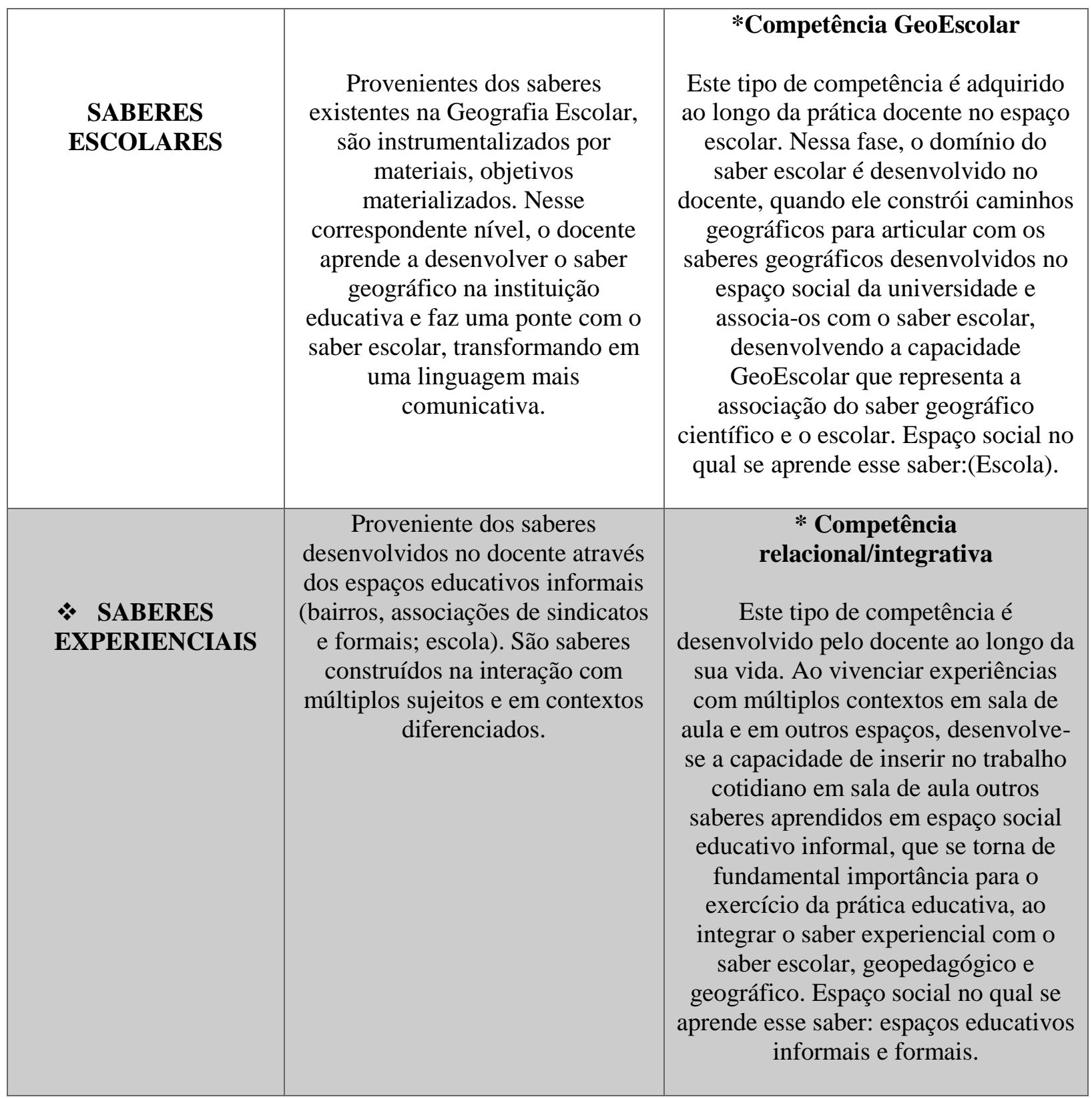

Fonte: Elaboração própria, 2019.

O quadro acima é um roteiro metodológico que ampliamos para auxiliar o professor de Geografia durante o exercício da prática docente em sala de aula. As fases que representam cada saber tornam-se um subsídio que oportuniza o mediador a compreender a implicância da experiência docente que influencia na prática educativa exercida no ambiente escolar.

Desse modo, Libâneo (2013) coloca que a didática se caracteriza como mediação que está fundamentada nas bases teóricas científicas da educação popular como também da prática docente, enquanto que a teoria pedagógica orienta a ação educativa escolar, mediante os objetivos, conteúdo, e a tarefa da formação cultural. Todavia, a ação educativa só pode realizar-se pela prática pedagógica do professor. 
$\mathrm{EM}$

Entende-se, portanto, que é através da prática pedagógica do professor que o ensino se concretiza como significativo e interessante para o educando, pois a didática torna-se um alicerce que encaminha e auxilia o docente a executar uma ação pedagógica significativa no ambiente educativo.

[...] é preciso que o próprio professor se reconheça como pesquisador, ou seja, que trilhe caminhos teóricos e metodológicos na busca de respostas para os desafios que encontra na relação pedagógica com os alunos e no diálogo com o espaço geográfico e com o mundo em mudança (CACETE; PAGANELLI; PONTUSCHKA, 2007, p.25).

Sendo assim, mediante a contemporaneidade, é crucial recontextualizar a prática docente mobilizando múltiplos saberes para promover um processo de aprendizado mais significativo para os estudantes. No trabalho docente, o mediador constrói múltiplos saberes que são relevantes para construir possibilidades de reconstruir a sua própria prática, atendendo à necessidade dos sujeitos - o que contribuirá para fortalecer competências para os professores.

Acreditamos que seja possível propor uma definição do saber que, embora não sendo aceita unanimemente por todos, possua uma forte carga de validade e uma quase universalidade, pelo menos em nossa tradição intelectual ocidental. Nessa perspectiva, acreditamos que não vale a pena inventar um novo conceito de saber para nosso uso pessoal (seria como inventar a roda); julgamos que seja preferível apoiar-se nas concepções existentes. Relembremos, portanto, essas concepções, mas de maneira bastante breve e sem entrar numa longa genealogia histórica ou numa discussão epistemológica sistemática. No âmbito da cultura da modernidade, o saber foi definido de três maneiras, em função de três "lugares" ou topos: a subjetividade, o julgamento e a argumentação (TARDIF, 2011, p. 193).

O saber docente torna-se uma ponte para construir caminhos estratégicos na reconstrução da prática educativa contextualizada com o organismo educacional da sala de aula - o que resulta no ensinar descobrindo saberes. Todavia, a competência dos saberes docentes não se restringe a uma receita pronta, pois o mediador aplicará o saber de acordo com a realidade no momento do seu ofício. Acredita-se, neste estudo, que o professor é o ator autônomo da própria competência pedagógica.

Os novos paradigmas de formação docente partem do reconhecimento da especificidade dessa formação, assim como da necessidade da revisão dos saberes constitutivos da docência, incluindo no viés a perspectiva da emancipação do profissional (CACETE; PAGANELLI e PONTUSCHKA, 2007). 
A atividade exercida no cotidiano escolar é uma fonte de conhecimento para que o sujeito que media o saber aprenda ensinando e reconstrua as ações pedagógicas de acordo com a situação do momento. Então, aqui, a experiência em sala de aula é um caminho que contribui para que as competências sejam consolidadas no agir pedagógico.

\section{A construção dos saberes no processo formativo do professor de geografia}

A formação inicial do professor de Geografia é o momento oportuno para fortalecer os saberes e a identidade docente. É nesse sentido que a sociedade contemporânea enfrenta desafios na formação nas universidades públicas. Dentre eles, temos a necessidade de possibilitar experiências no espaço educativo para o fortalecimento da competência pedagógica do mediador durante o processo formativo do graduando.

É nesse sentido que os saberes que fazem parte do arcabouço da grade curricular das disciplinas dos cursos de licenciaturas na educação superior são um dos elementos de suma significância para promover a formação do senso crítico, autônomo e consciente do papel que o docente desempenhará ao mediar os saberes na educação geográfica escolar.

Os professores de Geografia necessitam ter sólida formação científica, pedagógica e humanística. Além disso, é necessário conhecer a ciência geográfica e sua trajetória, mas não é o suficiente, é preciso saber ensiná-la. Desse modo, a Geografia, como ciência da sociedade e da natureza, constitui um ramo do conhecimento de fundamental importância para a formação inicial e continuada dos professores que têm ou terão a responsabilidade nas classes dos anos iniciais de alfabetização, assim como dos professores dos anos mais adiantados que trabalham com ela como disciplina escolar (CACETE; PAGANELLI e PONTUSCHKA, 2007, p. 25).

Desse modo, a trajetória do profissional, desde a formação inicial e continuada, é um processo com construção de saberes docentes que, ao serem inclusos de forma integrada na ação docente no espaço escolar, trilha caminhos para construir possibilidades de uma prática educativa de fato significativa para os estudantes.

Nesse sentido, o professor na formação inicial e continuada precisa compreender o próprio processo de construção do conhecimento escolar, além de entender as diferenças relativas ao conhecimento científico e o escolar (PEREIRA, 2000). 
$\mathrm{EM}$

Sendo assim, durante a formação do licenciando em Geografia, são mediados saberes da ciência geográfica de fundamental importância para a transposição da prática educativa em sala de aula. Esses saberes são o que constituem e fundamentam a corrente geográfica, oriundos da base epistemológica da ciência.

Os saberes disciplinares correspondem aos diversos campos do conhecimento que dispõem a sociedade e se encontram hoje integrados nas universidades sob a forma de disciplinas (TARDIF, 2011).

É pertinente, nesse estudo, elencar os saberes que são permeados ao longo do tempo na base epistemológica da ciência e que têm valor funcional de suma relevância na transposição didática do professor de Geografia. Para ser mediado de forma significativa, é crucial a integração dos outros saberes que porventura são aprendidos pelo docente ao exercer a prática profissional em sala de aula. São esses saberes que auxiliam no desempenho no exercício do trabalho diário no ambiente educativo.

[...] os próprios professores, no exercício de suas funções e na prática de sua profissão, desenvolvem saberes específicos, baseados em seu trabalho cotidiano e no conhecimento de seu meio. Esses saberes brotam da experiência e são por ela validados. Eles incorporam-se à experiência individual e coletiva sob a forma de hábitos e de habilidades, de saber- fazer e de saber -ser. (TARDIF, 2011, p. 38-39).

Diante disso, a prática educativa é aperfeiçoada durante o exercício constante no cotidiano em sala de aula. O processo de ensino/aprendizagem no espaço escolar é o que fortalece a competência pedagógica do mediador e, consequentemente, aperfeiçoa o aprender e ensinar na educação geográfica escolar. Contudo, é perceptível a real necessidade de integrar os diferentes saberes para fomentar caminhos para uma aprendizagem com sentido para os estudantes. Neste sentido, ensinar atribuindo significado no saber geográfico exige uma formação que capacite ao sujeito a competência de mobilizar na prática docente os saberes construídos na carreira inicial profissional e inter-relacionar com os saberes experienciais adquiridos com a prática educativa em sala de aula.

[...] assim, sua prática pedagógica requer de si reflexão crítica e constante criação e recriação do conhecimento e das metodologias de ensino, o que pressupõe uma atividade de investigação permanente que necessita ser apreendida e valorizada. Nesse sentido, é importante que os professores, em seu processo formativo, sobretudo, inicial, pesquisem como são produzidos os conhecimentos por eles ensinados (CACETE; PAGANELLI e PONTUSCHKA, 2007, p. 96). 
A disciplina de Geografia na educação geográfica escolar é um componente no currículo escolar que oportuniza os sujeitos a compreenderem a complexidade da dialética nos espaços, assim como entender o mundo vivido no seu entorno. Diante dessa premissa, para que o mediador oportunize caminhos metodológicos significativos para o desenvolvimento da aprendizagem geográfica nos educandos, é importante que, na formação inicial do educador, sejam proporcionados caminhos investigativos didáticos para que o profissional tenha a competência pedagógica de transpor os saberes para a prática e auxiliar o aluno no processo de construção de significado do saber geográfico.

A sala de aula ganha importância na formação do cidadão que se realiza ou mesmo se concretiza na possibilidade de um trabalho criativo que leve o aluno a pensar o mundo em que vive a partir de sua condição real de existência. $\mathrm{O}$ ato de conhecer transforma o indivíduo e sua condição no mundo, o que transporta para novos modos de ver o mundo. Desse modo, a sala de aula pode ser o locus privilegiado do exercício da crítica (inerente ao ato de conhecer), da possibilidade de manifestação do diferente, um espaço da informação do conhecimento, de alimentação da paixão pela descoberta, do estímulo e da reflexão. Assim, a geografia aparece como possibilidade de pensar o mundo real e a sociedade num mundo fragmentado, apesar de global (CARLOS, 2006, p. 8).

É nessa vertente que a sala de aula é um espaço que oportuniza ao docente investigar os possíveis caminhos para a construção de um processo de ensino/aprendizagem com significado para os estudantes. Diante disso, os saberes que são permeados pelo professor ao exercer a prática no ambiente educativo é o que apresenta subsídio para que o profissional desenvolva um agir pedagógico significativo na educação geográfica escolar, através dos procedimentos metodológicos e recursos didáticos.

É fundamental a diferenciação entre o saber universitário e o saber ensinado pelos professores, assim como entre o saber ensinado e o saber adquirido pelos alunos. Sendo assim, transformar o saber universitário, sem desfigurá-lo e nem o desvalorizar em objeto de ensino. Nesta perspectiva, supõe-se a transposição didática que nem vulgarize, nem empobreça o saber universitário, mas que apresente uma construção diferenciada objetivando atender ao público escolar (SIMIELI, 2006).

Ao ser integrada no agir pedagógico em sala de aula, a formação sólida que contemple o cidadão de forma integral, constituindo os saberes provenientes do arcabouço teórico do conhecimento possibilitado na formação inicial e continuada, assim como o saber adquirido pelo professor na prática do exercício docente. Desse modo, esses saberes constroem 
possíveis caminhos metodológicos para desenvolver a aprendizagem geográfica com sentido para os educandos.

Ensinar é agir com outros seres humanos, é saber agir com outros seres humanos que sabem o que lhes é ensinado. Desse modo, o saber não é uma substância ou conteúdo fechado em si mesmo, mas se manifesta através das relações entre professor e os alunos (TARDIF, 2011.

É possível considerar que a construção dos saberes no processo formativo do professor de Geografia é permeada de significância ao ser integrado cada tipo de saber no exercício da prática cotidiana em sala de aula e, consequentemente, impulsiona para atribuir significado ao saber geográfico mediado no ambiente educativo. É nesse viés que compreender os diferentes tipos de saberes que são construídos na formação inicial e continuada do graduando é também entender a relevância para a transposição didática do docente nas aulas de Geografia na educação geográfica escolar.

Pensar pedagogicamente os saberes geográficos, numa perspectiva metodológica e significativa para os alunos, implica em ações que reestruturem os conteúdos, e consequentemente, inovem os procedimentos didáticos estabelecendo clareza nos objetivos (CASTELAR, 2010).

Diante dessa vertente sobre a construção dos saberes na formação do professor de Geografia, o desafio no processo formativo encontra-se destinado às instituições de ensino superior nos cursos de licenciaturas, para que possibilite, na grade curricular, disciplinas que contemplem o arcabouço teórico e prático e auxiliem na compreensão da importância de transpor os saberes de forma integrada, além dos saberes científicos e pedagógicos na formação do professor para a prática educativa.

[...] espera-se da licenciatura que desenvolva nos alunos conhecimentos e habilidades, atitudes e valores que lhes possibilitem permanentemente irem construindo seus saberes-fazeres docentes a partir das necessidades e desafios que o ensino como prática social lhes coloca no cotidiano. Esperase, pois, que mobilize os conhecimentos da teoria da educação e da didática necessários à compreensão do ensino como realidade social, e que desenvolva neles a capacidade de investigar a própria atividade para, a partir dela, constituírem e transformarem os seus saberes-fazeres docentes, num processo de construção de suas identidades como professores (PIMENTA, 1999, p. 18).

Diante desse contexto, o processo formativo na educação superior, ao fomentar a articulação dos saberes adquiridos durante a formação e os saberes práticos vivenciados no cotidiano em sala de aula, conduz para a competência pedagógica do docente em atuar em 
diferentes espaços e dilemas, assim como na habilidade de mediar o saber com mais significado para os estudantes. No caso do professor de Geografia, possibilita-se que o mediador, durante o processo de aprendizagem, promova uma educação geográfica que comtemplará a habilidade de atuar ressignificando a prática docente que perpassa a mera transmissão de conteúdo, mas mediar o saber geográfico para que o aluno compreenda as contradições apresentadas no espaço geográfico e possa ser capaz de reconhecer a complexidade da sociedade contemporânea.

\section{Considerações finais}

Diante da temática contextualizada sobre os saberes docentes na educação geográfica neste estudo, compreende-se a relevância dos saberes dos professores de Geografia para promover a didática dos saberes docentes na construção do conhecimento geográfico em sala de aula através da pesquisa bibliográfica.

A mobilização dos saberes geopedagógicos, escolares, geográficos e experienciais tornam-se um possível caminho para uma didática dos saberes geográficos na educação geográfica, o que fortalece as competências dos professores e permite a possibilidade de uma ação no espaço escolar que influencie nas aprendizagens geográficas dos estudantes.

Este trabalho torna-se relevante para os professores da educação básica por permitir uma contextualização, através de um aporte teórico que esclarece sobre a relevância da ampliação dos saberes, buscando efetivar a prática pedagógica do professor de Geografia e na educação geográfica.

O presente estudo é direcionado para os graduandos e graduados de diferentes licenciaturas, além, dos pesquisadores que estudam o ensino de Geografia e outras áreas que, através desse artigo, poderão obter conhecimento sobre a contribuição das pluralidades dos saberes para o exercício da prática docente em sala de aula, assim como direciona para relevância na educação geográfica escolar.

Este artigo possibilita a comunidade científica e escolar entender a respeito da compreensão em torno da predominância significativa que os saberes docentes têm para a consolidação da competência da prática pedagógica do mediador e, consequentemente, para a aprendizagem geográfica dos educandos. 
EM

QUESTÃO

V.14 N. $01 \bullet 2021$

pág. 58-76

\section{Referências}

ALARCÃO, I. Professores Reflexivos em uma escola reflexiva. 8. ed. Cortez, São Paulo, 2011.

CACEte, N, H; PAgAnelli, T, I; PONTUSCHKA, N, N. Para Ensinar e Aprender Geografia. 1 ed. São Paulo, Cortez, 2007.

CALLAI, H.C. A Geografia ensinada: os desafios de uma educação geográfica. In: MORAIS, E, M, B. MORAES, L, B (org.). Formação de professores: conteúdos e metodologias no ensino de Geografia. Goiânia, Nepeg.2010. Cap.: 1.p.15-38.

CARloS, A, F, A. A Geografia em sala de aula. São Paulo. Ed. 8 Contexto, 2006.

CASTELAR, S. M. V. Educação geográfica: formação e didática. In: MORAIS, E, M, B. MORAES, L.B. (org). Formação de professores: conteúdos e metodologias no ensino de geografia. Goiânia, NEPEG, (2010). Cap.2. p. 39-57.

CAVALCANTI, L.S. Base teórica e metodológica da Geografia: uma referência para a formação e a prática de ensino. In: DALVA. E. GONÇALVES.R (org.). Formação de professores: concepções e práticas em geografia. GOIÂNA E.V. 2006. Cap.2. p. 27-49.

CHARLOT, B. Da relação com o saber às práticas educativas. São Paulo. Cortez, 2014.

FREIRE, P. Pedagogia da autonomia: Saberes necessários para a prática educativa. Ega,2002.

GERHARDT, T.E. SILVEIRA, D.T. Método de pesquisa. Universidade Aberta do Brasil UAB/UFRGS e pelo Curso de Graduação Tecnológica - Planejamento e Gestão para o Desenvolvimento Rural da SEAD/UFRGS. - Porto Alegre: Editora da UFRGS, 2009.

Disponível em: http://www.ufrgs.br/cursopgdr/downloadsSerie/derad005.pdf. Acesso em 03/11/2018.

LAKATOS, E, M. MARCONI, E, L. Fundamentos de metodologia científica. - 5. ed. - São Paulo. Atlas 2003.

LIBÂNEO, J. C. Didática. 2. ed. São Paulo, Cortez, 2013.

MACEDO, L. Ensaios construtivistas. In: MACEDO, L. (Org). O construtivismo e sua função educacional. São Paulo, casa do psicólogo, 1994. Cap. 3, p.13-25. Disponível em: https://books.google.com.br/books?hl=ptBR\&lr=\&id=xR33CjKsFwMC\&oi=fnd\&pg=PA1\&d $\mathrm{q}=\mathrm{LIVRO}+\mathrm{O}+\mathrm{CONSTRUTIVISMO \& ots}=0$ liteX8B7q\&sig=n3j8q2rdjQhTmqFeeDzq_tn9C8 \#v=onepage \&q=LIVRO\%200\%20CONSTRUTIVISMO\&f=true. Acesso em 03/02/2021.

PEREIRA, D. A. A dimensão pedagógica na formação do geógrafo. Terra Livre, São Paulo, v.14, 2000. 
PIMENTA, S. G. Formação de professores: identidade e saberes da docência. In: PIMENTA, Selma Garrido. (Org.). Saberes pedagógicos e atividade docente. São Paulo: Cortez Editora, p.15-34.1999.

PIRES, Lucineide Mendes. A Prática Pedagógica do Professor de Geografia no Ensino Fundamental. Dissertação (Mestrado em Geografia). Universidade Federal de Goiás, Instituto de Estudos Sócio-Ambientais, Programa de Pesquisa e Pós-Graduação em Geografia. Goiânia, 2009.

SACRAMENTO, A, C.M. Didática e Educação Geográfica: algumas notas. Universidade de São Paulo, Brasil,2010.

SAVIANI, D. Pedagogia Histórico-Crítica: primeiras aproximações. Campinas, SP, 2011.

SIMIELLI, M, E, R. Cartografia no Ensino Fundamental e Médio. In: CARLOS, A, F, A (org.). A Geografia em sala de aula. São Paulo. Ed. 8 Contexto, 2006. Cap:7. p. 92-108.

TARDIF, M. Saberes docentes e formação profissional. Ed. 12, Petrópolis, Vozes, 2011. 